\title{
Photophysical Properties of Cyclometalated Platinum(II) Diphosphine Compounds in the Solid State and in PMMA Films
}

\author{
Belle Coffey, Lily Clough, Daphne D. Bartkus, Ian C. McClellan, Matthew W. Greenberg, \\ Christopher N. LaFratta, Joseph M. Tanski, and Craig M. Anderson*
}
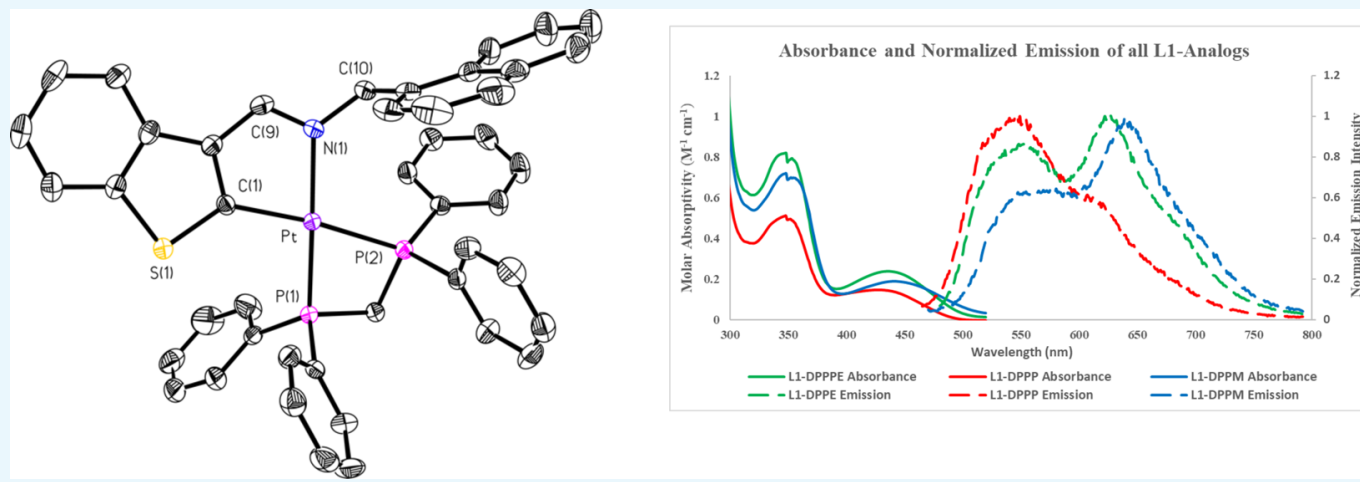

ABSTRACT: Platinum(II) compounds were synthesized with both chelate cyclometalated ligands and chelate diphosphine ligands. The cyclometalated ligands include phenylpyridine and a benzothiophene-containing ligand. The three new benzothiophene compounds were characterized by nuclear magnetic resonance (NMR) spectroscopy, high-resolution mass spectrometry (HR-MS), and photophysical measurements. In the case of one compound, L1-DPPM, the structure was determined by single crystal X-ray diffraction. The structural coherence of the noncrystalline emissive solid state was measured by X-ray total scattering real space pair distribution function analysis. Quantum yield values of all of the platinum compounds measured in the solid state and in PMMA films were much greater than in solution.

\section{INTRODUCTION}

Phosphorescent organometallic complexes have application potential in devices due to their tunable and efficient luminescent properties. $^{1-3}$ Due to these complexes' emissive properties, they are widely studied for their application in fields such as bioimaging, chemical sensors, organic light-emitting diodes, and light-emitting electrochemical cells. ${ }^{4-7}$ Specifically, the photoluminescent properties of organometallic $\mathrm{Pt}$ (II) complexes have been reported and widely studied. ${ }^{8-12}$ The luminescent properties of these complexes are likely due to the presence of strong carbon donors, the inclusion of aromatic rings, and the large spin-orbit coupling of the heavy metal platinum center. ${ }^{5,13,14}$ Additionally, the photophysical properties of $\mathrm{Pt}(\mathrm{II})$ complexes can be tuned by altering the ligand environment of the coordination compound, ${ }^{11}$ including changes to cyclometalated ligands and/or the auxiliary ligands. $8,14,15$

In this study, a class of benzothiophene-based (Figure 1, L1) cyclometalated $\mathrm{Pt}(\mathrm{II})$ complexes with chelating bis(diphenylphosphino) ligands (Figures 1 and 2) was synthesized and characterized, and their photophysical properties were recorded in different states. The chelating $\mathrm{C}^{\wedge} \mathrm{N}$ ligand $\mathbf{L} \mathbf{1}$<smiles>C(=N/Cc1cccc2ccccc12)\c1csc2ccccc12</smiles>

L1

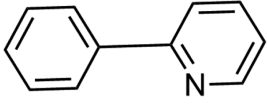

PPY
Figure 1. $\mathrm{C}^{\wedge} \mathrm{N}$ Ligands used in this study.

contains a strong sigma donor carbon atom formed by $\mathrm{C}-\mathrm{H}$ activation cyclometalation. Recently, a report comparing platinum compounds with thiophene-containing ligands and phenylpyridine ligands, and a variety of auxiliary ligands has been published. ${ }^{8}$ We look to examine how a change to a benzothiophene and an imine-derived ligand would affect the

Received: August 18, 2021

Accepted: October 4, 2021

Published: October 14, 2021 


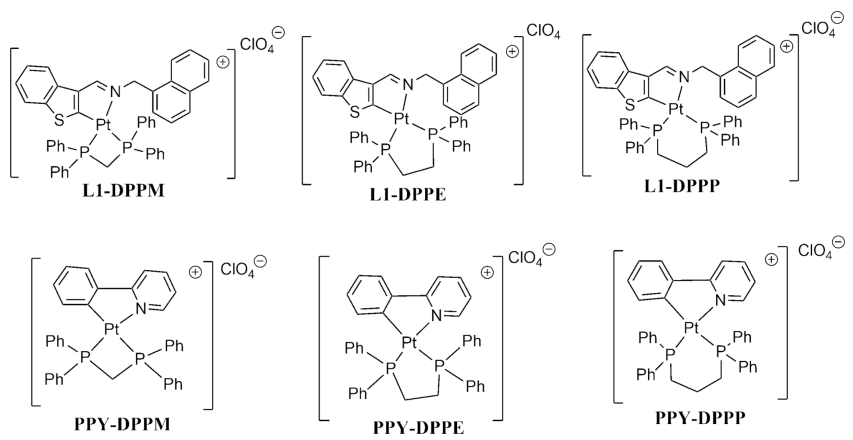

Figure 2. Cyclometalated Pt(II) complexes with chelating diphenylphosphine ligands.

photophysical properties of a set of platinum complexes. Additionally, benzothiophenes derivatives are synthesized and studied for their pharmaceutical applications. ${ }^{16,17}$ The inclusion of strong sigma donors has been used to improve the population of MLCT states by increasing the energy of the $\mathrm{d}-\mathrm{d}$ ligand field excited states, while varying excitation wavelength and electron-donor ability of the metals' ligands has changed the rates of intersystem crossing. ${ }^{8,18-21}$ Two $\mathrm{C}^{\wedge} \mathrm{N}$ ligands, with sigma donor properties, L1 and PPY (Figure 1), were utilized to synthesize six $\mathrm{Pt}(\mathrm{II})$ complexes with bis(diphenylphosphino) chelating ligands. This created two sets of monomeric $\mathrm{Pt}$ (II) complexes with either L1 or PPY as the $C^{\wedge} N$ chelate (Figure 2). The $C^{\wedge} N$ ligands' effects on the tunability of the photophysical properties of each complex were analyzed in various states. The cations of PPY-DPPM, PPY-DPPE, and PPY-DPPP (Figure 2) have been previously synthesized with different counterions, while the bis(dicyclohexylphosphino)alkane derivatives have been reported as perchlorate salts. $1,4,8,22-26$

Substantial differences in the photophysical properties of the PPY and L1 analogs were observed. The structural differences between PPY and L1 are important to understanding each ligand's effects on the photophysical properties of the complexes. The structure of $\mathbf{L} \mathbf{1}$ contains a thiophene moiety, while PPY does not, thus resulting in complexes that were blue-shifted compared to the red-shifted L1 analogs (vide infra).

If a phosphorescent complex has the potential for application in a device, then it is invaluable to consider the photoluminescent quantum yield. ${ }^{27-29}$ Photophysical properties of complexes are often evaluated in solutions, but in devices, these complexes are usually immobilized in a solid matrix. ${ }^{1,30}$ Polymethyl methacrylate (PMMA) doped films are easy to prepare and have been reported to drastically increase emissive properties compared to the solution phase, specifically the photoluminescent quantum yield of various $\mathrm{Pt}$ and $\mathrm{Ir}$ complexes. $8,9,11,27,31$ The emissive properties of all cyclometalated $\mathrm{Pt}(\mathrm{II})$ complexes (Figure 2) in this study were measured in the solution, in the solid state, and in the doped polymer (PMMA) film. As mentioned, the cations of PPYDPPM, PPY-DPPE, and PPY-DPPP have been reported for their catalytic and photoluminescent properties; ${ }^{1,4,22-25}$ however, to the best of our knowledge, there is no literature to date for the three PPY analogs presented here as perchlorate salts (Figure 2) in doped PMMA.

\section{RESULTS AND DISCUSSION}

Synthesis and Characterization. The complexes were synthesized and characterized by their ${ }^{1} \mathrm{H}$ and ${ }^{31} \mathrm{P}$ NMR and UV-vis spectra. The spectra for the PPY analogs with different counterions were consistent with previously published data. ${ }^{1,4}$ L1, a benzothiophene-imine functionalized $C^{\wedge} N$ ligand, was used in the chelate-assisted $\mathrm{C}-\mathrm{H}$ activation reaction to yield the monodentate $\mathrm{Pt}$ (II) complex L1-Met (see the Supporting Information). L1-Met subsequently underwent a substitution reaction yielding the desired Pt(II) complexes: L1-DPPE, L1DPPP, and L1-DPPM. Complexes L1-DPPE, L1-DPPP, and L1-DPPM were characterized by ${ }^{1} \mathrm{H}$ and ${ }^{31} \mathrm{P}$ NMR spectroscopy; HR-MS; and, in the case of L1-DPPM, single crystal Xray diffraction (SCXRD). A complex ion is formed when the neutral bisphosphine ligand substitutes for an anionic chloride ligand. The use of $\mathrm{LiClO}_{4}$ had the most success in precipitating the complexes compared to other ions such as chloride and hexafluorophosphate $\left(\mathrm{PF}_{6}^{-}\right)$. The complexes were purified through a Pasteur pipette silica column providing pure crystalline yellow and orange products in good yields (7791\%). All three L1 complexes have low solubility in many common solvents but are soluble in somewhat polar solvents such as DCM, acetonitrile, acetone, THF, and DMSO. All three complexes exhibit appropriate ${ }^{195} \mathrm{Pt}$ and ${ }^{31} \mathrm{P}$ coupling in both the ${ }^{1} \mathrm{H}$ NMR and ${ }^{31} \mathrm{P}$ NMR spectra, which aided in their characterization.

The ${ }^{1} \mathrm{H}$ NMR characterization relied heavily on the diagnostic methylene and imine peaks ${ }^{32}$ of the chelated L1 ligand $^{10}$ and on the alkyl chain protons of the various bis(diphenylphosphino) ligands. For example, the ${ }^{1} \mathrm{H}$ NMR of L1-DPPM clearly displayed the imine resonance as a doublet at $8.90 \mathrm{ppm}\left({ }^{3} \mathrm{Jt}_{\mathrm{Pt}-\mathrm{H}}=44 \mathrm{~Hz},{ }^{3} J_{\mathrm{H}-\mathrm{P}}=9 \mathrm{~Hz}\right)$, the methylene of $\mathbf{L} \mathbf{1}$ as a singlet at $5.33 \mathrm{ppm}\left({ }^{3} J_{\mathrm{Pt}-\mathrm{H}}=14 \mathrm{~Hz}\right)$, and the methylene of the bis(diphenylphosphino)methane as a triplet at $5.12 \mathrm{ppm}$ $\left({ }^{3} J_{\mathrm{Pt}-\mathrm{H}}=40 \mathrm{~Hz},{ }^{3} J_{\mathrm{Pt}-\mathrm{P}}=21 \mathrm{~Hz}\right)$. The ${ }^{31} \mathrm{P}$ NMR spectra of all three compounds corroborate the proposed structures. Two resonances were observed each with ${ }^{195} \mathrm{Pt}$ satellites, thus confirming one phosphorus trans to the nitrogen of the L1 ligand and the other phosphorus atom trans to the carbon donor of L1. For example, in the ${ }^{31} \mathrm{P}$ NMR spectrum of L1DPPM, the resonance of the phosphorus that is trans to the nitrogen of $\mathbf{L} \mathbf{1}$ appeared at $-40.9 \mathrm{ppm}$ and exhibited both ${ }^{31} \mathrm{P}$ and ${ }^{195} \mathrm{Pt}$ coupling $\left({ }^{1} J_{\mathrm{Pt}-\mathrm{P}}=3000 \mathrm{~Hz},{ }^{2} J_{\mathrm{P}-\mathrm{P}}=110 \mathrm{~Hz}\right)$, whereas the resonance of the phosphorus atom trans to the strong carbon donor appeared at $-35.3 \mathrm{ppm}$ and exhibited both phosphorus and platinum coupling $\left({ }^{1} J_{\mathrm{Pt}-\mathrm{P}}=1800 \mathrm{~Hz},{ }^{2} J_{\mathrm{P}-\mathrm{P}}=\right.$ $110 \mathrm{~Hz}$ ), with a significantly lower ${ }^{195} \mathrm{Pt}-\mathrm{P}$ coupling constant. $^{33,34}$ The structure of L1-DPPM was determined by an X-ray diffraction study. Bond lengths and angles were within the accepted range for platinum(II) compounds (Figure 3)..$^{35-38}$

Photophysical Measurements. The absorbance spectra, lifetimes of excited states, emission spectra, and quantum yield values have been previously reported for the three PPY analogs as chloride salts; however, it appears that values have not been measured or reported in doped PMMA thin films for perchlorate salts. Therefore, we have included values for these complexes to compare and contrast the L1 compounds. ${ }^{1,4,22,23}$ All luminescent properties were measured in the solution (Figure 4), in the solid state, and in a PMMA thin film (95\% wt PMMA, 5\% wt Pt complexes) (Figure 5 and Table 1). Observing a similar pattern to the PPY analogs, each 


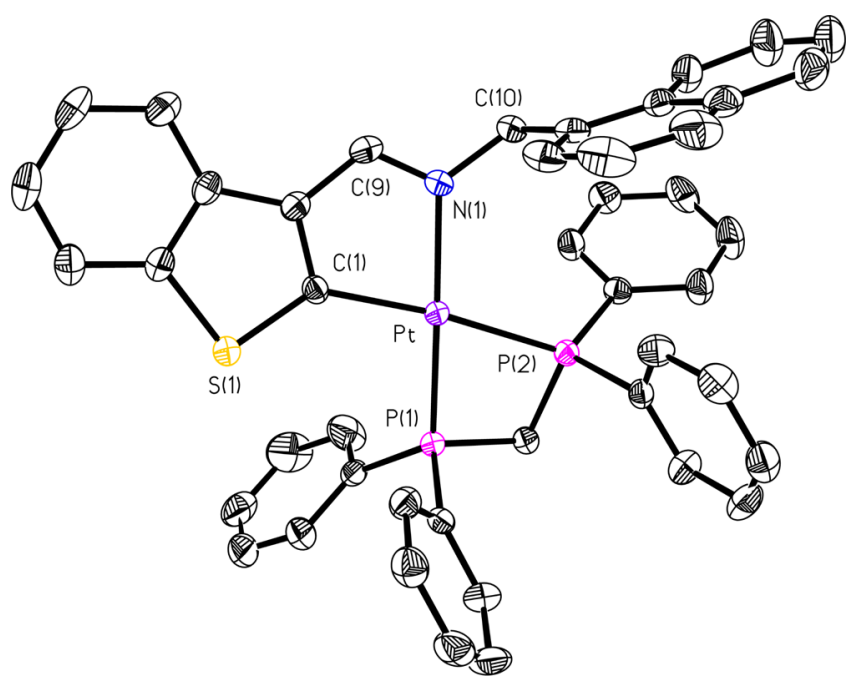

Figure 3. ORTEP of compound L1-DPPM ( $50 \%$ probability thermal ellipsoids). Selected bond lengths $(\AA)$ and angles $\left({ }^{\circ}\right)$ : Pt-C(1): 2.034 (2); Pt-N(1): 2.116 (2); Pt-P(1): 2.2309 (6); Pt-P(2): 2.3218 (6); C(1)-Pt-N(1): 78.27 (8); C(1)-Pt-P(1): 102.04 (7); N(1)-Pt-P(1): 173. 64 (6); C(1)-Pt-P(2): 173.70 (6); N(1)-Pt-P(2): 107.70 (5); and $\mathrm{P}(1)-\mathrm{Pt}-\mathrm{P}(2): 71.80$ (2).

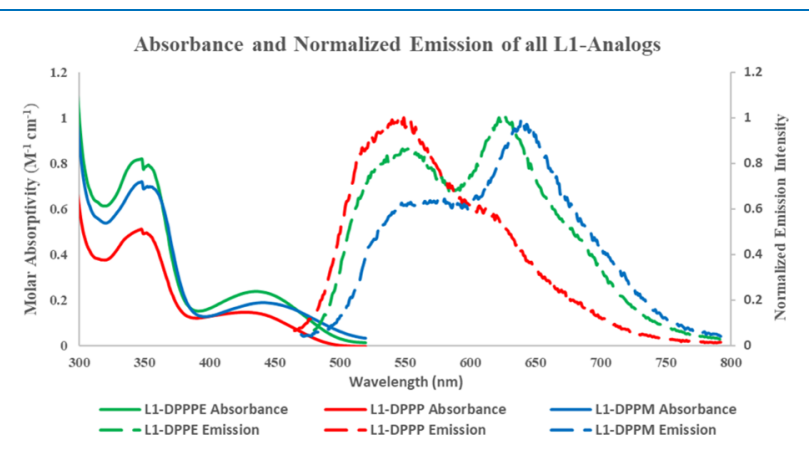

Figure 4. Absorbance and normalized emission spectra of all L1 analogs in the $\mathrm{CH}_{2} \mathrm{Cl}_{2}$ solution.

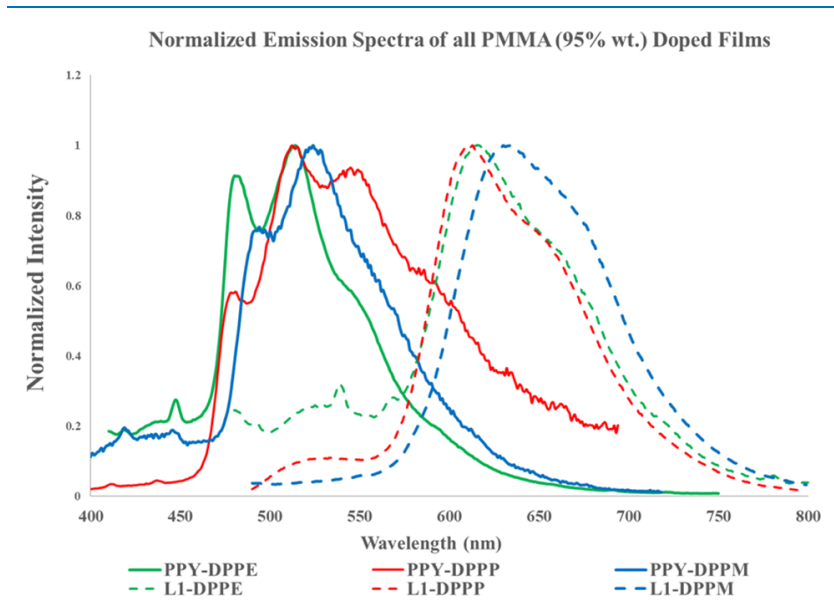

Figure 5. Normalized emission spectra of all selected compounds (5\% $w t)$ in doped PMMA film (95\% wt).

L1 compound became more emissive in the solid state and slightly more emissive still in the PMMA films. ${ }^{4}$ All L1 platinum complexes absorbed blue light ranging from 430 to $450 \mathrm{~nm}$, with L1-DPPM absorbing the lowest energy wavelength at $450 \mathrm{~nm}$. These peaks for all three complexes, L1-DPPE, L1-DPPM, and L1-DPPP, had molar extinction
Table 1. Absorption and Emission Data of Selected Complexes $^{a}$

\begin{tabular}{|c|c|c|c|c|c|}
\hline compound & $\begin{array}{l}\text { absorption } \\
\text { peak }(\mathrm{nm})\end{array}$ & $\begin{array}{c}\text { extinction } \\
\text { coefficient } \\
\left(\times 10^{3} \mathrm{M}^{-1}\right. \\
\left.\mathrm{cm}^{-1}\right)\end{array}$ & $\begin{array}{c}\text { emission } \\
\text { peaks in } \\
\text { solution } \\
(\mathrm{nm})\end{array}$ & $\begin{array}{l}\text { emission } \\
\text { peaks in } \\
\text { solid state } \\
(\mathrm{nm})\end{array}$ & $\begin{array}{c}\text { emission } \\
\text { peaks in } \\
\text { PMMA } \\
\text { film }(\mathrm{nm})\end{array}$ \\
\hline L1-DPPP & 435 & 1.4 & 550,620 & 520,620 & 540,650 \\
\hline L1-DPPE & 430 & 2.3 & 550,640 & 550,640 & 550,620 \\
\hline L1-DPPM & 450 & 1.8 & 580,640 & 670 & 640 \\
\hline $\begin{array}{l}\text { PPY- } \\
\text { DPPP }^{b}\end{array}$ & 355 & 2.2 & $\begin{array}{l}431 \\
(\max )\end{array}$ & 480,550 & 480,520 \\
\hline $\begin{array}{l}\text { PPY- } \\
\text { DPPE }^{b}\end{array}$ & 355 & 2.8 & $\begin{array}{l}431 \\
(\max )\end{array}$ & 490,520 & 490,520 \\
\hline $\begin{array}{l}\text { PPY- } \\
\text { DPPM }^{b}\end{array}$ & 360 & 2.1 & $\begin{array}{l}431 \\
(\max )\end{array}$ & 490,520 & 480,520 \\
\hline
\end{tabular}

${ }^{a}$ Solution samples were recorded in DCM at $0.1 \mathrm{mM}$. Excited wavelength for emission spectra was the lowest energy peak for each compound. ${ }^{b}$ These values compare reasonably to those previously reported for the PPY complex cations. ${ }^{4}$

coefficients ranging from $1.3 \times 10^{3}$ to $2.3 \times 10^{3}$ (Table 1 ). Extinction coefficients on the order of $10^{3}$ have been shown in the literature to represent MLCT bands for platinum species. ${ }^{39}$ The PPY analogs, however, absorbed higher energy wavelengths, ranging from 370 to $385 \mathrm{~nm}$, similar to the cations previously reported. $4,22,23$

The emissive properties of the two sets (L1 versus PPY) of analog complexes differed significantly. The solution spectra of all L1 analogs contained two emission peaks, one higher energy wavelength peak around $550 \mathrm{~nm}$ and an intense orange peak at around $630 \mathrm{~nm}$, whereas the phenyl-pyridine analogs had emission peaks at higher energies between 400 and 500 $\mathrm{nm} .{ }^{4}$ By comparing the dashed traces in Figures 4 and 5, it can be observed that, when immobilized in PMMA films, the higher energy peak of each $\mathbf{L} \mathbf{1}$ complex is greatly reduced but there is very little change in the lower energy emission wavelengths at 620-640 nm (Figure 5). This supports the idea that immobilization in PMMA films encourages predominately phosphorescence, as the higher energy bands may be due to fluorescence in solution. ${ }^{40,41}$ Luminescent lifetimes were recorded for all new $\mathbf{L} \mathbf{1}$ analogs. Lifetime values were recorded in the solution, solid state, and PMMA films (Table S1). The lifetime measurements for the emission peaks assigned to the higher energy bands with a bathochromic shift of approximately $100 \mathrm{~nm}$ were in the 6-14 ns range and thus suggest a fluorescence assignment. However, the lower energy bands with a bathochromic shift of approximately $200 \mathrm{~nm}$ all had longer lifetimes in the hundreds of nanoseconds, consistent with phosphorescence. ${ }^{20,39,42,43}$ The lifetime values of each L1 complex drastically increased when the lifetime measurements were recorded in the complexes' aggregate states. For example, in the solution, L1-DPPP had an observed lifetime of $146 \mathrm{~ns}$ (Table S1), which increased approximately $600 \%$ in the solid state ( $905 \mathrm{~ns}$ ) and by $700 \%$ in a PMMA film (1054 ns). The longer lifetimes support the idea of increased phosphorescence and luminescent properties of these complexes in aggregate forms, such as the solid state and PMMA films. ${ }^{40,42}$

PPY-DPPM, PPY-DPPE, and PPY-DPPP were all weakly emissive in solution yet bright emitters in their solid state and PMMA films. This phenomenon has been previously reported and is referred to as aggregate-induced emission., ${ }^{1,44-46} \mathrm{~A}$ similar pattern was observed with the $\mathbf{L} \mathbf{1}$ analogs. An emission spectrum in solution could be observed for all L1 analogs; however, they were weak in intensity, similar to the PPY 
analogs. In contrast, when the emission spectra were recorded in the solid state and PMMA films, the complexes became bright emitters.

The increased luminescence of the doped films is quite evident when analyzing the quantum yield data of the compounds (Table 2). As mentioned, all PPY and L1-derived

Table 2. Photoluminescent Quantum Yield Values (\%) for Studied Complexes

$\begin{array}{lccc}\text { compound } & \text { solution } & \text { solid state } & \text { PMMA film } \\ \text { L1-DPPP } & 0.25 & 5.4 & 15 \\ \text { L1-DPPE } & 0.30 & 7.3 & 13 \\ \text { L1-DPPM } & 0.21 & 4.8 & 12 \\ \text { PPY-DPPP } & 0.28 & 6.2 & 15 \\ \text { PPY-DPPE } & 0.02 & 4.2 & 24 \\ \text { PPY-DPPM } & 0.04 & 18 & 30\end{array}$

complexes were weak emitters in solution and had quantum yields of less than $1 \%$. These values in the solution were recorded relative to $\left[\mathrm{Ru}(\text { bipy })_{3}\right] \mathrm{Cl}_{2}$ as no signals were detectable using an integrating sphere. ${ }^{47,48}$ The solid-state and PMMA measurements were recorded with an integrating sphere, and quantum yield values in the solid state ranged from 2 to $18 \%$. PPY-DPPM had the most efficient solid-state photoluminescent quantum yield at $18 \%$, whereas the rest of the complexes had solid-state quantum efficiencies ranging from 2 to $7 \%$ (Table 2). In the solid state, with the exception of PPY-DPPM, there is no significant difference in quantum yields between the L1 and PPY analogs.

The quantum yield of each complex increases further when immobilized in a PMMA film. The quantum yield doubles and in some cases triples (Table 2) for the complexes. PPY-DPPM has the highest quantum yield at $30 \%$ in a PMMA film. The PMMA films of the L1 compounds range from 12 to $15 \%$. The PPY films have higher quantum yields ranging from 15 to $30 \%$; however, in both sets of analogs, there is a sharp increase in quantum yields when doped into a polymer film compared to the solid state.

Generally, the photoluminescent quantum yield of a complex is determined by the relative rates of different transitions throughout the relaxation process. ${ }^{6,28,29}$ The amount of intersystem crossing and the internal conversion are important nonradiative transitions that influence the quantum yields of the complexes. When a complex is immobilized as a dopant in a polymer film, there is restricted molecular motion. Since motion is restricted in the polymer matrix, the rate of nonradiative transitions decreases. ${ }^{30}$

TD-DFT and DFT Calculations. DFT and TD-DFT calculations were run on the $\mathbf{L} \mathbf{1}$ complexes to help assign the observed electronic transitions in absorbance spectroscopy. All complexes were optimized at the B3LYP/LANL2DZ level of theory. The results of geometry optimization of L1-DPPM in either gas phase or with implicit solvation show reasonable agreement to the structure observed in the solid state by SCXRD (Table S2 and Figure 3).

TD-DFT calculations were compared to the electronic spectra of the three L1 analogs. The TD-DFT simulations of absorbance spectra successfully reproduce the major features experimentally observed in the absorbance spectra for the L1 complexes (Figure 6 and Figures S1 and S2). The TD-DFT (hole particle) natural transition orbitals of the high oscillator strength transitions can generally be described as primarily a

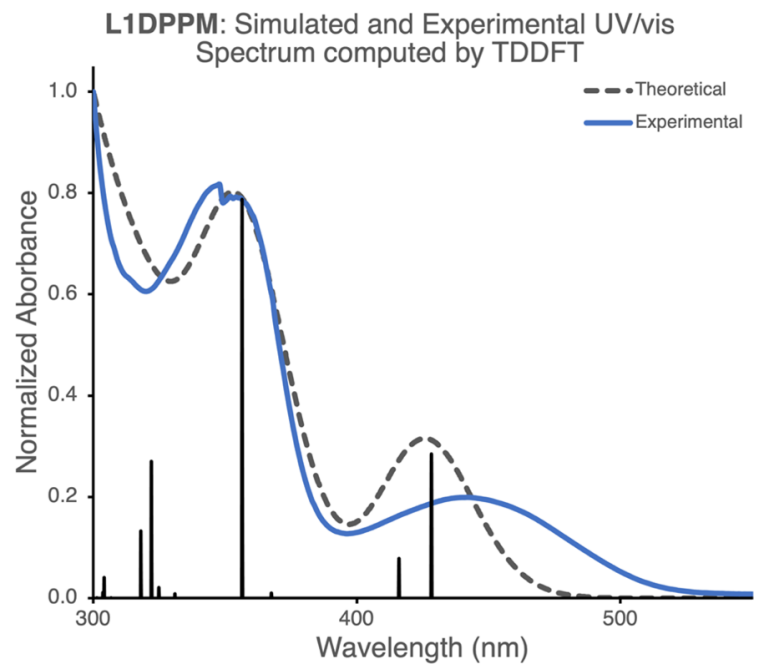

Figure 6. Observed UV-vis absorbance spectrum (solid line) and simulated UV-vis spectrum (dashed line) for L1-DPPM. Observed theoretical spectrum arises from three high oscillator strength transitions at 428,356 , and $322 \mathrm{~nm}$ corresponding to TD-DFTcalculated vertical excitations $S_{1}, S_{4}$, and $S_{7}$.

transition between single pairs of FMOs or near FMOs (Table 3, Table S3, Figure 7, and Figures S3-S10). The intense S1

Table 3. TD-DFT-Calculated Vertical Excitations of High Oscillator Strength Transitions and Coefficients of Principal Contributing Orbital Transition

$\begin{array}{ccccc}\mathrm{S}_{n} & \begin{array}{c}\text { excitation } \\ \text { energy } \\ (\mathrm{nm})\end{array} & \begin{array}{c}\text { oscillator } \\ \text { strength }\end{array} & \begin{array}{c}\text { principal } \\ \text { contributing } \\ \text { transitions }\end{array} & \begin{array}{r}\text { coefficient of principal } \\ \text { contributing transition }\end{array} \\ \mathrm{S}_{1} & 428 & 0.0380 & \begin{array}{c}\text { HOMO }-2 \text { to } \\ \text { LUMO }\end{array} & 0.96165 \\ \mathrm{~S}_{4} & 356 & 0.1050 & \begin{array}{c}\text { HOMO }-1 \text { to } \\ \text { LUMO +1 }\end{array} & 0.97513 \\ \mathrm{~S}_{7} & 322 & 0.0360 & \begin{array}{c}\text { HOMO to } \\ \text { LUMO }\end{array} & 0.97937\end{array}$

band in the lower energy visible region can be described as a mixed metal to ligand charge transfer/intraligand charge transfer (MLCT/ILCT). For this transition, the hole NTO is concentrated on the electron-rich benzothiophene moiety and the filled platinum $d$ orbital, and the particle NTO of clear $\pi^{*}$ character, largely in the L1 platinacycle $\pi$ system. Higher energy intense transitions show a similar hole/particle character. An intense S4 transition appears to be localized on the naphthyl ligand fragment $\pi$ system in the hole NTO and empty $d_{x^{2}-y^{2}}^{2}$ orbital, both platinacycles, and one of the $\mathrm{PPh}_{3}$ phenyl rings $\pi$ systems in the particle NTO.

Real Space X-ray Pair Distribution Function Analysis. Aggregation-induced emission (AIE) in the solid state has been invoked previously in other similar transition metal complexes where photoluminescent quantum yield enhancement is observed in the solid state as compared to the solution state. $^{1,44-46}$ To measure the structural coherence of the emissive solid state for our $\mathbf{L} \mathbf{1}$ complexes, we performed X-ray total scattering real space pair distribution function analysis (PDF). While many emissive molecular solids are not amenable to X-ray structural analysis by traditional Bragg diffraction, the use of $\mathrm{X}$-ray $\mathrm{PDF}$ analysis can resolve atomic structural information in crystalline, disordered/nanocrystal- 

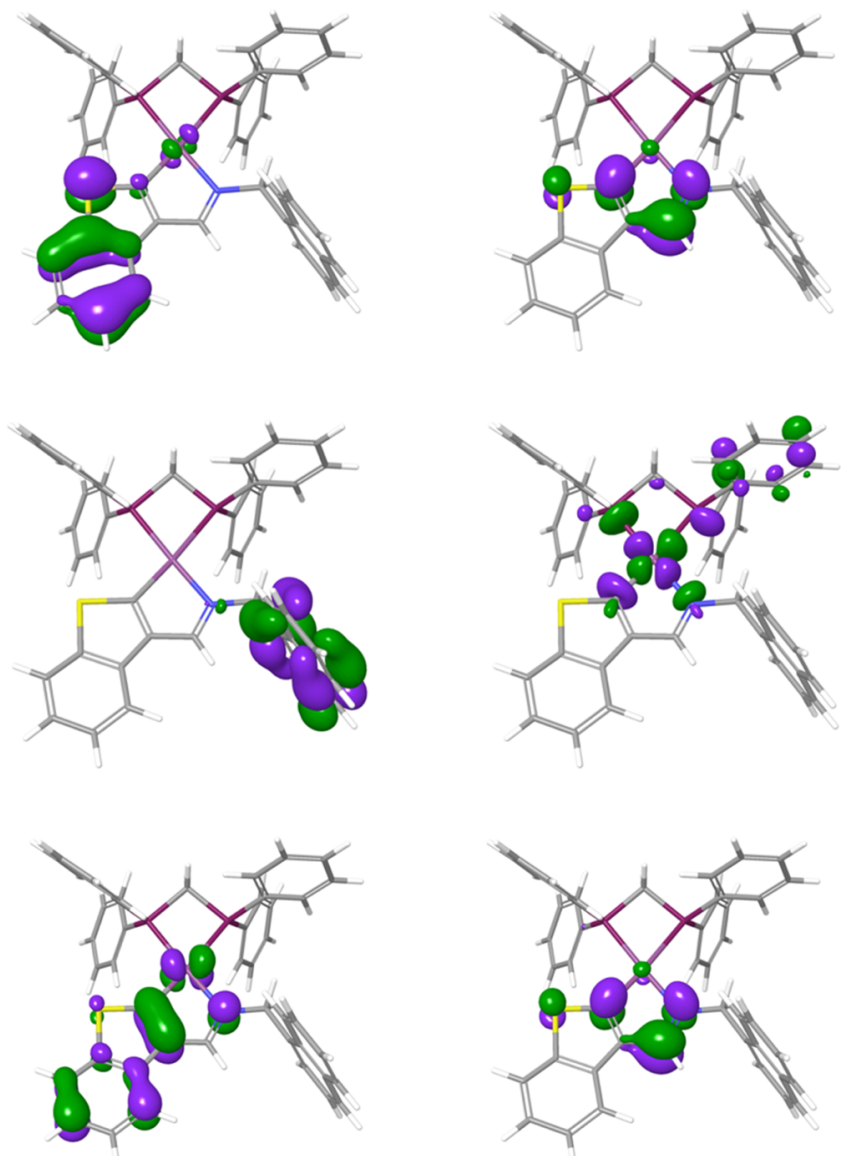

Figure 7. NTOs for high oscillator strength transitions. Hole (left) and particle (right) NTOs for $S_{1}, S_{4}$, and $S_{7}$ in Table 3 .

line, amorphous, and molecular solids. The reduced X-ray pair distribution function $G(r)$ represents the probability of finding two atoms separated at a pair distance $r$ and is obtained by the Fourier transform of the properly normalized total scattering structure function $F(Q)$. $^{49}$

Reduced pair distribution functions, $G(r)$, of L1-DPPM, L1DPPE, and L1-DPPP were recorded in the solid state and showed a highly disordered molecular solid. As illustrated in Figure 8, which shows L1-DPPM, the observed $G(r)$ is consistent with prior measurements of molecular solids showing sharp well-defined intramolecular correlations at low $r$ (below $r \sim 3.7 \AA$ ), poorly defined broad density oscillations representing disordered intermolecular correlations at higher $r$ (at above $r \sim 8.0 \AA$ ), and an intermediate region containing both inter- and intramolecular correlations (Figures 8 and 9).$^{50-53}$ Significantly, there is little evidence of a well-defined atomic order past $1 \mathrm{~nm}$ in these samples, suggesting a highly disordered emissive solid state.

Similar results are seen for L1-DPPE and L1-DPPP, with one substantial difference being a notable shift of the most intense intramolecular correlation for L1-DPPP, reflecting in part overlapping distances from the $\mathrm{Pt}-\mathrm{L}$ coordination sphere and the relatively large $Z$ of $\mathrm{Pt}$, to higher $r$ (Figure 9). This behavior is consistent with simulations of $G(r)$ from Debye scattering equation calculations using DFT optimized structures and represents the elongation of the $\mathrm{Pt}-\mathrm{L}$ bond lengths caused by geometrical distortion from the larger propyl linker (Figure S11 and Table S2). In general, the intramolecular $G(r)$ is well modeled by refinements of the atomic

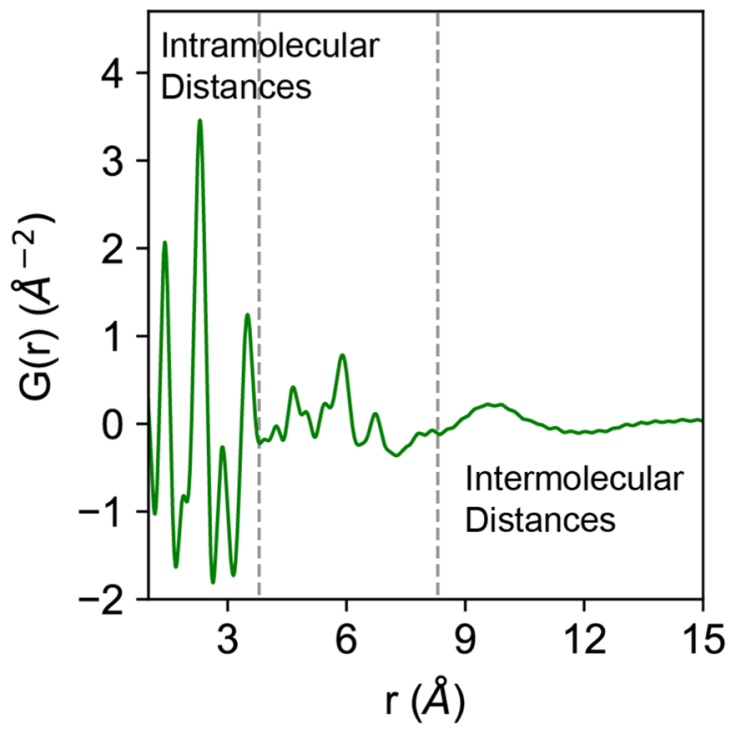

Figure 8. Reduced X-ray pair distribution function, $G(r)$, of L1DPPM illustrating representative intramolecular, intra- + intermolecular, and intermolecular atom-atom distance regions observed for the solids.

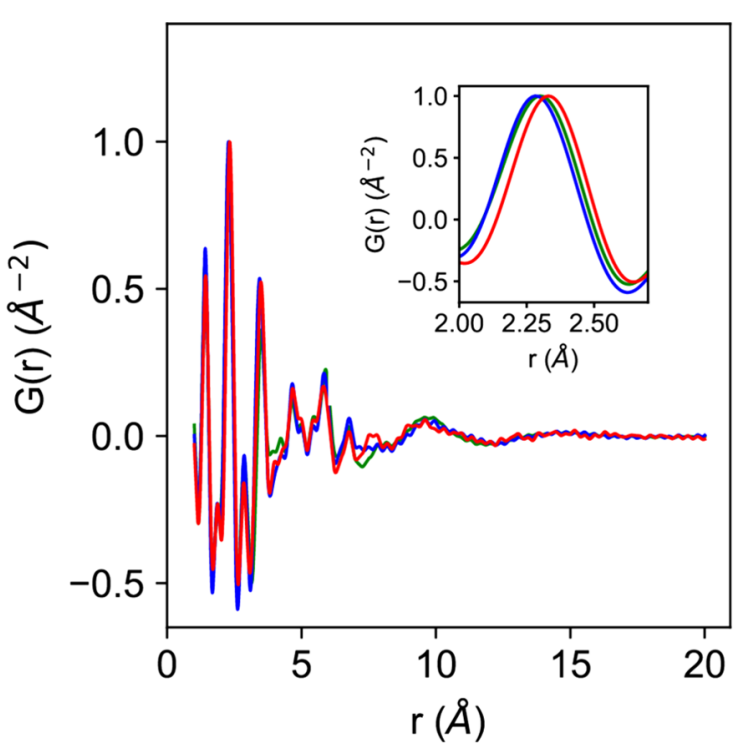

Figure 9. Reduced X-ray pair distribution function, $G(r)$, of L1DPPM (green), L1-DPPE (blue), and L1-DPPP (red) over full-r and around $\mathrm{Pt}-\mathrm{L}$ interatomic distances (inset). The $G(r)$ for each sample is normalized to unity at the most intense correlation to aid in comparing the structure of each sample.

structure of the molecular unit (Figure S12). The results from PDF analysis suggest that enhanced emissive properties arise from a highly disordered solid state in our complexes, as our observations are consistent with structural coherence not persisting more than a couple of molecular units. This is consistent with other prior literature reports of solid-state photoluminescence enhancement or aggregate-induced emission from both crystalline and amorphous samples, which show that long-range translational order is not a necessary condition for AIE effects. ${ }^{54-57}$ 


\section{CONCLUDING REMARKS}

Three $\mathrm{Pt}(\mathrm{II})$ complexes with the chelating benzothiopheneimine functionalized ligand $\mathbf{L} 1$ were synthesized and characterized, and their photophysical properties were measured and compared to PPY cations. Each complex and its phenyl-pyridine analog were used as dopants in PMMA films to study the photophysical effects of altering the ligand structure in thin films. All complexes were weakly emissive in solution but became bright emitters in their solid state and when immersed in a PMMA film. All L1 cyclometalated Pt(II) complexes showed evidence of being aggregate-induced emitters, $^{44}$ similarly to their phenyl pyridine analogs, ${ }^{1}$ as quantum yield values significantly increased from the complexes' solution state to its solid state and PMMA doped film. This emissive solid state was observed to be amorphous from total X-ray scattering PDF analysis, and the AIE effect likely arises from local structural rigidity rather than long-range rigid crystalline order.

\section{EXPERIMENTAL SECTION}

General. Solvents and reagents were purchased from Sigma Aldrich unless otherwise noted. $\mathrm{K}_{2} \mathrm{PtCl}_{4}$ was purchased from the Pressure Chemical Company. NMR spectra were recorded at Bard College using a Varian MR-400 MHz spectrometer $\left({ }^{1} \mathrm{H}, 400 \mathrm{MHz} ;{ }^{13} \mathrm{C}, 100.6 \mathrm{MHz} ; 31 \mathrm{P}, 162 \mathrm{MHz}\right.$ and referenced to $\left.\mathrm{SiMe}_{4}\left({ }^{1} \mathrm{H},{ }^{13} \mathrm{C}\right)\right)$. Shifts are given in $\mathrm{ppm}$ and coupling constant $J$ values in $\mathrm{Hz}$. Abbreviations used are as follows: $\mathrm{s}=$ singlet, $\mathrm{d}=$ doublet, $\mathrm{t}=$ triplet, and $\mathrm{m}=$ multiplet. Electrospray mass spectra were performed at Vassar College using an LC/MSD-TOF spectrometer.

Computational Details. Calculations were carried out using TD-DFT and DFT implemented in the Jaguar 9.1 suite of $a b$ initio quantum chemistry programs. ${ }^{58}$ Geometry optimizations were performed with the B3LYP functional using a mixed basis set consisting of LANL2DZ with an effective core potential for the Pt atom and the 6-31-G** for all other atoms. All final structures were confirmed to be energetic minima by harmonic vibrational analysis. In the case of the TD-DFT calculations, the UV-vis absorbance spectra were simulated by optimization of the first 25 excited states and the use of a CPCM implicit solvation model of dichloromethane to improve energetic agreement to the experimental UV-vis spectra. The resulting vertical excitation energies are convoluted with a Gaussian function of $34 \mathrm{~nm}$ half width for the purposes of visualization. The initial geometry guess was generated using crystallographic data molecular mechanics as implemented in Avogadro ${ }^{59}$ version 1.2.0 using the UFF force field.

Photophysical Measurements. Quantum yield (QY) measurements were taken using a PTI QM400 (Horiba) equipped with a petite integrating sphere and a 920C cooled PMT detector. The emission spectra were corrected using a SLS200 stabilized tungsten-halogen light (Thorlabs) as a calibration source. Measurements of solutions were done in 1 $\mathrm{cm}$ path length quartz cuvette (FireflySci, Inc.), while measurements of powders and films were taken using a Teflon powder holder. For powders, a quartz window was used with the holder, but this was removed for film measurements. PMMA thin films were fabricated through a drop casting method. Approximately $5 \mathrm{mg}$ of the platinum species was dissolved in $2 \mathrm{~mL}$ of DCM. A ratio of 5 to $95 \%$ wt was used to calculate the correct weight of PMMA to add to the solution.
PMMA was slowly added to the stirring solution. Once all PMMA had dissolved, the solution was slowly dropped onto optical-grade cover glass and allowed to dry overnight. Films could then be cut and placed in the powder holder for QY measurements or supported on glass for steady-state measurements. During QY measurements, slit sizes were adjusted and/ or neutral density filters were used to keep the fluorescence signal in the linear range of the detector ( $<1 \mathrm{Mcps})$. Excitation and emission slits were typically set to $\sim 1 \mathrm{~nm}$ passband. To confirm the instrument's performance, a $5 \mu \mathrm{M}$ solution of rhodamine 101 (Millipore Sigma, CAS 116450-56-7) in ethanol was measured using an excitation wavelength of 552 $\mathrm{nm}$, and the emission was collected from 560 to $800 \mathrm{~nm}$. The QY of the fluorescence was measured six times with an average value of 0.91 . The manufacturer's instruction manual states that the QY should be $0.92 \pm 0.04$. We also confirm the instrument's performance using a weaker emitter, harmaline (Millipore Sigma, CAS 304-21-2), which has a literature QY of $0.32 \pm 0.02$. $^{.0}$ We measured a $10 \mu \mathrm{M}$ solution of harmaline in a $\mathrm{pH} 2$ solution acidified with $\mathrm{H}_{2} \mathrm{SO}_{4}$ four times at an excitation wavelength of $367 \mathrm{~nm}$ over an emission range of 380-700 nm with an average QY of 0.34. Additionally, we confirmed the instrument's performance with a weakly emitting sample, tris(bipyridine)ruthenium(II)chloride, in an aqueous solution at $10 \mu \mathrm{M}$. The sample was measured three times with an excitation wavelength of $436 \mathrm{~nm}$ over an emission range of $460-760 \mathrm{~nm}$ with an average QY of 0.021 and compared to the literature value of 0.028 . $^{47}$ Steady-state emission spectra were recorded using a PTI QM-40 instrument with a PMT detector, which is sensitive up to $850 \mathrm{~nm}$. The luminescence lifetimes of the complexes were measured by time-correlated single-photon counting following excitation with a 365 or $450 \mathrm{~nm}$ LED in methylene chloride solution or by placing solid samples in the sample holder.

X-ray Diffraction. L1-DPPM was crystallized by slow diffusion of pentane into an acetone solution. X-ray diffraction data were collected on a Bruker APEX 2 CCD platform diffractometer $(\mathrm{Mo} \mathrm{Ka}(1=0.71073 \AA))$ at $125 \mathrm{~K}$ with crystals mounted in a nylon loop with Paratone-N cryo-protectant oil. The structure of L1-DPPM was solved using direct methods (SHELXT 2014/5) ${ }^{61}$ and standard difference map techniques and was refined by full-matrix least-squares procedures on $F^{2}$ (SHELXL 2017/1). ${ }^{62}$ All nonhydrogen atoms were refined anisotropically.

X-ray Total Scattering Measurements and Pair Distribution Function Analysis Data Reduction. Total scattering measurements were performed using the 28-ID-2 (XPD) high energy X-ray Powder Diffraction beamline at the National Synchrotron Light Source II (NSLS-II), Brookhaven National Laboratory. X-ray scattering data were collected using a large-area 2D PerkinElmer detector $(2048 \times 2048$ pixels, 200 $\times 200 \mu \mathrm{m}^{2}$ each) in rapid acquisition mode with a sample-todetector distance of $232 \mathrm{~mm} .{ }^{63}$ The incident energy of the Xrays was $67.29 \mathrm{keV}(\lambda=0.1842 \AA)$. Samples were prepared in $1.5 \mathrm{~mm}$ Kapton polyimide tubes and sealed with modeling clay. Beamline calibration was performed with a $\mathrm{Ni}$ powder standard. Raw 2D detector intensities were azimuthally integrated and converted to $1 \mathrm{D} I(Q)$, where $Q=\frac{4 \pi \sin \theta}{\lambda}$ is the magnitude of the elastic scattering momentum transfer, using pyFAI. ${ }^{64}$ Background subtraction, polarization correction, and normalization to the total scattering structure function $F(Q)$ and Fourier transformation to obtain the pair 
distribution function (PDF) $G(r)$ were performed using the reduction methods of PDFgetX3 implemented in the xPDFsuite. ${ }^{65,66}$ The range of scattering vector used in the Fourier transform to obtain the $G(r)$ was chosen to optimize the tradeoff between real space resolution and statistical noise $\left(Q_{\max }=18 \AA^{-1}\right.$, Figure S13). PDF simulations and refinement of $G(r)$ to experimental data were performed using a custom code written in Python utilizing PDF calculators and refinement tools from the Diffpy-CMI complex modeling framework. $^{67}$ More information on refined parameters and output is contained in Figure S12.

Preparation of Compounds. See the Supporting Information for additional experimental details, including copies of NMR spectra, UV/vis spectra, and emission spectra. $\left[\mathrm{Pt}(\mathrm{dmso})_{2} \mathrm{Cl}_{2}\right]$ was synthesized according to a previously published procedure. ${ }^{68} \mathbf{L 1}$ and L1-Met were synthesized ${ }^{10,69}$ according to a modification of known procedures ${ }^{70}$ and can be found in the Supporting Information.

L1-DPPE $\left[\mathrm{Pt}\left(\mathrm{C}_{20} \mathrm{H}_{15} \mathrm{SN}\right)\left(\mathrm{Ph}_{2} \mathrm{PCH}_{2}\right)_{2}\right) \mathrm{ClO}_{4}$. L1-Met $(0.10$ $\mathrm{g}, 0.16 \mathrm{mmol})$ and bis(diphenylphosphino)ethane $(0.060 \mathrm{~g}$, $0.16 \mathrm{mmol}$ ) were dissolved in acetonitrile $(25 \mathrm{~mL})$. The resulting mixture was stirred and heated at $80^{\circ} \mathrm{C}$ for $1 \mathrm{~h}$. $\mathrm{LiClO}_{4}$ (3 equiv) was added, and the solution was heated for $30 \mathrm{~min}$. The solution was gravity filtered to remove solids, and the solvent was removed by rotary evaporation, yielding a yellow solid. The product was purified through a Pasteur pipette silicon column using 10:1 DCM/acetone as the eluent, and the solid obtained after removal of the solvent was characterized by ${ }^{1} \mathrm{H}$ and ${ }^{31} \mathrm{P}$ NMR spectroscopies. Yield: $91 \%$ (0.13 g, $0.14 \mathrm{mmol}) .{ }^{1} \mathrm{H} \mathrm{NMR}\left(400 \mathrm{MHz}, \mathrm{CD}_{2} \mathrm{Cl}_{2}\right): \delta 2.47$ $\left(\mathrm{m}, 4 \mathrm{H},\left(\mathrm{CH}_{2}\right)_{2}\right), 5.01,\left(\mathrm{~s}, 2 \mathrm{H}, \mathrm{CH}_{2}, J_{\mathrm{Pt}-\mathrm{H}}=16.0 \mathrm{~Hz}\right), 7.13-$ 7.90 (aromatics), $8.19\left(\mathrm{~d}, 1 \mathrm{H}, \mathrm{CH},{ }^{2} \mathrm{~J}_{\mathrm{P}-\mathrm{H}}=8.8 \mathrm{~Hz},{ }^{3} \mathrm{~J}_{\mathrm{Pt}-\mathrm{H}}=85.8\right.$ $\mathrm{Hz}){ }^{31} \mathrm{P}$ NMR $\left(161 \mathrm{MHz}, \mathrm{CD}_{2} \mathrm{Cl}_{2}\right): \delta 37.5\left(\mathrm{~d},{ }^{1} \mathrm{~J}_{\mathrm{Pt}-\mathrm{P}}=3356\right.$ $\left.\mathrm{Hz},{ }^{3} J_{\mathrm{P}-\mathrm{P}}=4.6 \mathrm{~Hz}\right), 48.9\left(\mathrm{~d},{ }^{1} J_{\mathrm{Pt}-\mathrm{P}}=2249 \mathrm{~Hz},{ }^{3} J_{\mathrm{P}-\mathrm{P}}=4.6 \mathrm{~Hz}\right)$. ESI-HR-MS $(m / z)$ : found: $m / z$ 893.1861, calcd for $\left[\mathrm{C}_{46} \mathrm{H}_{38} \mathrm{NP}_{2} \mathrm{PtS}^{+}\right]: m / z$ 893.1848.

L1-DPPM $\left[\mathrm{Pt}\left(\mathrm{C}_{20} \mathrm{H}_{15} \mathrm{SN}\right)\left(\mathrm{CH}_{2}\left(\mathrm{PPh}_{2}\right)_{2}\right)\right] \mathrm{ClO}_{4}$. L1-Met $(0.060 \mathrm{~g}, 0.10 \mathrm{mmol})$ and bis(diphenylphosphino)methane $(0.040 \mathrm{~g}, 0.10 \mathrm{mmol})$ were dissolved in dichloromethane (15 $\mathrm{mL}$ ). The resulting mixture was stirred and heated at $40{ }^{\circ} \mathrm{C}$ under inert conditions for $1 \mathrm{~h} . \mathrm{LiClO}_{4}$ (3 equiv) was then added to the stirring mixture and was heated for $30 \mathrm{~min}$. The solution was gravity filtered to remove solids, and then the solvent was removed using rotary evaporation. The resulting yellow oil was purified through a Pasteur pipette silicon column using 10:1 DCM/acetone as the eluent. The isolated product was characterized by ${ }^{1} \mathrm{H}$ and ${ }^{31} \mathrm{P}$ NMR spectroscopies. Yield: $80 \%(0.07 \mathrm{~g}, 0.07 \mathrm{mmol}) .{ }^{1} \mathrm{H}$ NMR $(400 \mathrm{MHz}$, $\left.\mathrm{CD}_{2} \mathrm{Cl}_{2}\right): \delta 4.67\left(\mathrm{t}, 2 \mathrm{H}, \mathrm{CH}_{2},{ }^{2} \mathrm{~J}_{\mathrm{P}-\mathrm{H}}=10.8 \mathrm{~Hz},{ }^{3} J_{\mathrm{Pt}-\mathrm{H}}=55.0\right.$ $\mathrm{Hz}$ ), 7.22-7.84 (aromatics), $8.33\left(\mathrm{~d}, 1 \mathrm{H}, \mathrm{CH},{ }^{3} J_{\mathrm{Pt}-\mathrm{H}}=88.0 \mathrm{~Hz}\right.$, $\left.{ }^{2} J_{\mathrm{P}-\mathrm{H}}=8.6 \mathrm{~Hz}\right){ }^{31} \mathrm{P} \mathrm{NMR}\left(161 \mathrm{MHz}, \mathrm{CD}_{2} \mathrm{Cl}_{2}\right): \delta-41.0(\mathrm{~d}$, $\left.{ }^{1} J_{\mathrm{Pt}-\mathrm{P}}=2978 \mathrm{~Hz},{ }^{2} J_{\mathrm{P}-\mathrm{P}}=51 \mathrm{~Hz}\right),-35.3\left(\mathrm{~d},{ }^{1} J_{\mathrm{Pt}-\mathrm{P}}=1828 \mathrm{~Hz}\right.$, $\left.{ }^{2} J_{\mathrm{P}-\mathrm{P}}=51 \mathrm{~Hz}\right)$. ESI-HR-MS $(m / z)$ : found: $m / z 879.1703$, calcd for $\left[\mathrm{C}_{45} \mathrm{H}_{36} \mathrm{NP}_{2} \mathrm{PtS}^{+}\right]: m / z$ 879.1691.

L1-DPPP $\left[\mathrm{Pt}\left(\mathrm{C}_{20} \mathrm{H}_{15} \mathrm{SN}\right)\left(\mathrm{Ph}_{2} \mathrm{P}\left(\mathrm{CH}_{2}\right)_{3} \mathrm{PPh}_{2}\right)\right] \mathrm{ClO}_{4}$. L1-Met $(0.030 \mathrm{~g}, 0.04 \mathrm{mmol})$ and bis(diphenylphosphino)propane $(0.020 \mathrm{~g}, 0.04 \mathrm{mmol})$ were dissolved in dichloromethane (10 $\mathrm{mL})$. The resulting mixture was stirred and heated at $40{ }^{\circ} \mathrm{C}$ under inert conditions for $1 \mathrm{~h}$. $\mathrm{LiClO}_{4}$ (3 equiv) was then added to the stirring mixture and was heated for $30 \mathrm{~min}$. The solution was gravity filtered to remove solids, and then the solvent was removed by rotary evaporation. The resulting yellow oil was purified through a Pasteur pipette silicon column using 10:1 DCM/acetone as the eluent. The isolated solid product was characterized by ${ }^{1} \mathrm{H}$ and ${ }^{31} \mathrm{P}$ NMR spectroscopies. Yield: $77 \%$ (0.02 g, $0.03 \mathrm{mmol}) .{ }^{1} \mathrm{H}$ NMR $\left(400 \mathrm{MHz}, \mathrm{CD}_{2} \mathrm{Cl}_{2}\right): \delta 2.04\left(\mathrm{~s}, 2 \mathrm{H}, \mathrm{CH}_{2}\right), 2.46\left(\mathrm{~s}, 2 \mathrm{H}, \mathrm{CH}_{2}\right)$, $2.58\left(\mathrm{~s}, 2 \mathrm{H}, \mathrm{CH}_{2}\right), 4.71\left(\mathrm{~s}, 2 \mathrm{H}, \mathrm{CH}_{2}\right), 6.96-8.00$ (aromatics), $8.06\left(\mathrm{~d}, 1 \mathrm{H}, \mathrm{CH},{ }^{4} \mathrm{~J}_{\mathrm{P}-\mathrm{H}}=7 \mathrm{~Hz},{ }^{3} J_{\mathrm{Pt}-\mathrm{H}}=82.4 \mathrm{~Hz}.\right){ }^{31} \mathrm{P} \mathrm{NMR}$ $\left(161 \mathrm{MHz}, \mathrm{CD}_{2} \mathrm{Cl}_{2}\right): \delta-4.9\left(\mathrm{~d},{ }^{1} J_{\mathrm{Pt}-\mathrm{P}}=3301 \mathrm{~Hz},{ }^{2} J_{\mathrm{P}-\mathrm{P}}=29\right.$ $\mathrm{Hz}),-0.40\left(\mathrm{~d},{ }^{1} J_{\mathrm{Pt}-\mathrm{P}}=2146 \mathrm{~Hz},{ }^{2} J_{\mathrm{P}-\mathrm{P}}=29 \mathrm{~Hz}\right)$. ESI-HR-MS $(m / z)$ : found: $m / z$ 907.2008, calcd for $\left[\mathrm{C}_{47} \mathrm{H}_{40} \mathrm{NP}_{2} \mathrm{PtS}^{+}\right]: m / z$ 907.2004.

\section{ASSOCIATED CONTENT}

\section{(S) Supporting Information}

The Supporting Information is available free of charge at https://pubs.acs.org/doi/10.1021/acsomega.1c04509.

Additional figures and tables; DFT and TD-DFT calculation results; and experimental details and spectra (PDF)

Compound L1-DPPM (CIF)

\section{AUTHOR INFORMATION}

\section{Corresponding Author}

Craig M. Anderson - Department of Chemistry \& Biochemistry, Bard College, Annandale-on-Hudson, New York 12504, United States; 이이이.org/0000-0001-58754380; Phone: 845-752-2356; Email: canderso@bard.edu; Fax: 845-752-2339

\section{Authors}

Belle Coffey - Department of Chemistry \& Biochemistry, Bard College, Annandale-on-Hudson, New York 12504, United States

Lily Clough - Department of Chemistry \& Biochemistry, Bard College, Annandale-on-Hudson, New York 12504, United States

Daphne D. Bartkus - Department of Chemistry \& Biochemistry, Bard College, Annandale-on-Hudson, New York 12504, United States

Ian C. McClellan - Department of Chemistry \& Biochemistry, Bard College, Annandale-on-Hudson, New York 12504, United States

Matthew W. Greenberg - Department of Chemistry \& Biochemistry, Bard College, Annandale-on-Hudson, New York 12504, United States; (1) orcid.org/0000-0002-50813099

Christopher N. LaFratta - Department of Chemistry \& Biochemistry, Bard College, Annandale-on-Hudson, New York 12504, United States

Joseph M. Tanski - Department of Chemistry, Vassar College, Poughkeepsie, New York 12604, United States

Complete contact information is available at:

https://pubs.acs.org/10.1021/acsomega.1c04509

\section{Notes}

The authors declare no competing financial interest. CCDC for compound L1-DPPM is available at www.ccdc.cam. ac.uk/data_request/cif.

\section{ACKNOWLEDGMENTS}

This material is based upon work supported by the US National Science Foundation under CHE-1665435 (C.M.A., 
P.I.). We also acknowledge the Bard Summer Research Institute (BSRI) for support. This research used X-ray Powder Diffraction (XPD) beamline 28-ID-2 of the National Synchrotron Light Source II, a U.S. Department of Energy (DOE) Office of Science User Facility operated for the DOE Office of Science by Brookhaven National Laboratory (BNL) under Contract DE-SC0012704. M.W.G. acknowledges support from BNL Laboratory Directed Research and Development (LDRD) project 20-031. Mass spectrometry was run at Vassar College with the help of Karen Wovkulich, and we thank her. We thank Sanjit K. Ghose for valuable discussions on X-ray PDF data.

\section{REFERENCES}

(1) Pasha, S. S.; Alam, P.; Dash, S.; Kaur, G.; Banerjee, D.; Chowdhury, R.; Rath, N.; Roy Choudhury, A.; Laskar, I. R. Rare Observation of "aggregation Induced Emission" in Cyclometalated Platinum(II) Complexes and Their Biological Activities. RSC Adv. 2014, 4, 50549-50553.

(2) Shafikov, M. Z.; Daniels, R.; Pander, P.; Dias, F. B.; Williams, J. A. G.; Kozhevnikov, V. N. Dinuclear Design of a Pt(II) Complex Affording Highly Efficient Red Emission: Photophysical Properties and Application in Solution-Processible OLEDs. ACS Appl. Mater. Interfaces 2019, 11, 8182-8193.

(3) Lázaro, A.; Cunha, C.; Bosque, R.; Pina, J.; Ward, J. S.; Truong, K.-N. N.; Rissanen, K.; Lima, J. C.; Crespo, M.; Seixas de Melo, J. S.; et al. Room-Temperature Phosphorescence and Efficient Singlet Oxygen Production by Cyclometalated Pt(II) Complexes with Aromatic Alkynyl Ligands. Inorg. Chem. 2020, 59, 8220-8230.

(4) Aghakhanpour, R. B.; Nabavizadeh, S. M.; Rashidi, M.; Kubicki, M. Luminescence Properties of Some Monomeric and Dimeric Cycloplatinated(II) Complexes Containing Biphosphine Ligands. Dalton Trans. 2015, 44, 15829-15842.

(5) Fang, B.; Zhu, Y.; Hu, L.; Shen, Y.; Jiang, G.; Zhang, Q.; Tian, X.; Li, S.; Zhou, H.; Wu, J.; et al. Series of $\mathrm{C}^{\wedge} \mathrm{N}^{\wedge} \mathrm{C}$ Cyclometalated Pt(II) Complexes: Synthesis, Crystal Structures, and Nonlinear Optical Properties in the Near-Infrared Region. Inorg. Chem. 2018, 57, 14134-14143.

(6) MacDougall, S. K. W.; Ivaturi, A.; Marques-Hueso, J.; Krämer, K. W.; Richards, B. S. Ultra-high photoluminescent quantum yield of $\beta$ $\mathrm{NaYF}_{4}: 10 \% \mathrm{Er}^{3+}$ via broadband excitation of upconversion for photovoltaic devices. Opt. Express 2012, 20, A879-A887.

(7) Murphy, L.; Williams, J. A. G. Luminescent Platinum Compounds: From Molecules to OLEDs. In Topics in Organometallic Chemistry; Bozec, H. Ed.; 2010; pp. 75-111, DOI: 10.1007/978-3642-018.

(8) Li, K.; Tong, G. S. M.; Yuan, J.; Ma, C.; Du, L.; Yang, C.; Kwok, W.-M.; Phillips, D. L.; Che, C.-M. Excitation-Wavelength-Dependent and Auxiliary-Ligand-Tuned Intersystem-Crossing Efficiency in Cyclometalated Platinum(II) Complexes: Spectroscopic and Theoretical Studies. Inorg. Chem. 2020, 59, 14654-14665.

(9) Li, G.; Zhan, F.; Zheng, J.; Yang, Y. F.; Wang, Q.; Chen, Q.; Shen, G.; She, Y. Highly Efficient Phosphorescent Tetradentate Platinum(II) Complexes Containing Fused 6/5/6 Metallocycles. Inorg. Chem. 2020, 59, 3718-3729.

(10) Anderson, C. M.; Coffey, B.; Morales, L.; Greenberg, M. W.; Norman, M.; Weinstein, M.; Brown, G.; Tanski, J. M. Platinum Complexes from C-H Activation of Sterically Hindered $\left[\mathrm{C}^{\wedge} \mathrm{N}\right]$ Donor Benzothiophene Imine Ligands: Synthesis and Photophysical Properties. ACS Omega 2020, 5, 26855-26863.

(11) Sicilia, V.; Arnal, L.; Chueca, A. J.; Fuertes, S.; Babaei, A.; Muñoz, A. M. I.; Sessolo, M.; Bolink, H. J. Highly Photoluminescent Blue Ionic Platinum-Based Emitters. Inorg. Chem. 2020, 59, 11451152 .

(12) Gandioso, A.; Valle-Sistac, J.; Rodríguez, L.; Crespo, M.; FontBardía, M. Platinum(II) Compounds Containing Cyclometalated Tridentate Ligands: Synthesis, Luminescence Studies, and a Selective Fluoro for Methoxy Substitution. Organometallics 2014, 33, 561-570.
(13) Barzegar-Kiadehi, S. R.; Golbon Haghighi, M.; Jamshidi, M.; Notash, B. Influence of the Diphosphine Coordination Mode on the Structural and Optical Properties of Cyclometalated Platinum(II) Complexes: An Experimental and Theoretical Study on Intramolecular Pt $\cdots \mathrm{Pt}$ and $\Pi \cdots \pi$ Interactions. Inorg. Chem. 2018, 57, 5060-5073.

(14) Yersin, H.; Rausch, A. F.; Czerwieniec, R.; Hofbeck, T.; Fischer, T. The Triplet State of Organo-Transition Metal Compounds. Triplet Harvesting and Singlet Harvesting for Efficient OLEDs. Coord. Chem. Rev. 2011, 255, 2622-2652.

(15) Yersin, H.; Yersin, H. Triplet Emitters for OLED Applications. Mechanisms of Exciton Trapping and Control of Emission Properties. Transit. Met. Rare Earth Compd. 2004, 241, 1-26.

(16) Kim, S.; Dahal, N.; Kesharwani, T. Environmentally Benign Process for the Synthesis of 2,3-Disubstituted Benzo[b]Thiophenes Using Electrophilic Cyclization. Tetrahedron Lett. 2013, 54, 43734376.

(17) Keri, R. S.; Chand, K.; Budagumpi, S.; Balappa Somappa, S.; Patil, S. A.; Nagaraja, B. M. An Overview of Benzo[b]ThiopheneBased Medicinal Chemistry. Eur. J. Med. Chem. 2017, 138, 10021033.

(18) Tan, R.; Song, D. C-H and C-S Activations of QuinolineFunctionalized Thiophenes by Platinum Complexes. Organometallics 2011, 30, 1637-1645.

(19) Dorn, M.; Kalmbach, J.; Boden, P.; Kruse, A.; Dab, C.; Reber, C.; Niedner-Schatteburg, G.; Lochbrunner, S.; Gerhards, M.; Seitz, M.; et al. Ultrafast and Long-Time Excited State Kinetics of an NIREmissive Vanadium(III) Complex I: Synthesis, Spectroscopy and Static Quantum Chemistry. Chem. Sci. 2021, 38-10790.

(20) Kozhevnikov, D. N.; Kozhevnikov, V. N.; Shafikov, M. Z.; Prokhorov, A. M.; Bruce, D. W.; Williams, J. A. G. Phosphorescence vs Fluorescence in Cyclometalated Platinum(II) and Iridium(III) Complexes of (Oligo)Thienylpyridines. Inorg. Chem. 2011, 50, 38043815

(21) Shafikov, M. Z.; Kozhevnikov, D. N.; Bodensteiner, M.; Brandl, F.; Czerwieniec, R. Modulation of Intersystem Crossing Rate by Minor Ligand Modifications in Cyclometalated Platinum(II) Complexes. Inorg. Chem. 2016, 55, 7457-7466.

(22) Zheng, G. Y.; Rillema, D. P.; DePriest, J.; Woods, C. Forbidden Electronic Transitions between the Singlet Ground State and the Triplet Excited State of Pt(II) Complexes. Inorg. Chem. 1998, 37, $3588-3592$.

(23) DePriest, J.; Zheng, G. Y.; Goswami, N.; Eichhorn, D. M.; Woods, C.; Rillema, D. P. Structure, Physical, and Photophysical Properties of Platinum(II) Complexes Containing Bidentate Aromatic and Bis(Diphenylphosphino)Methane as Ligands. Inorg. Chem. 2000, 39, 1955-1963.

(24) Kolář, M. H.; Hobza, P. Computer Modeling of Halogen Bonds and Other $\sigma$-Hole Interactions. Chem. Rev. 2016, 116, 5155-5187.

(25) Jamshidi, M.; Yousefi, R.; Nabavizadeh, S. M.; Rashidi, M.; Haghighi, M. G.; Niazi, A.; Moosavi-Movahedi, A.-A. Anticancer Activity and DNA-Binding Properties of Novel Cationic Pt(II) Complexes. Int. J. Biol. Macromol. 2014, 66, 86-96.

(26) Kvam, P.-I.; Puzyk, M. V.; Balashev, K. P.; Songstad, J.; Lundberg, C.; Arnarp, J.; Björk, L.; Gawinecki, R. Spectroscopic and Electrochemical Properties of Some Mixed-Ligand Cyclometalated Platinum(II) Complexes Derived from 2-Phenylpyridine. Acta Chem. Scand. 1995, 335-343.

(27) Na, H.; Lai, P.-N.; Cañada, L. M.; Teets, T. S. Photoluminescence of Cyclometalated Iridium Complexes in Poly(Methyl Methacrylate) Films. Organometallics 2018, 37, 3269-3277.

(28) Fischer, S.; Fröhlich, B.; Steinkemper, H.; Krämer, K. W.; Goldschmidt, J. C. Absolute Upconversion Quantum Yield of $\beta$ $\mathrm{NaYF}_{4}$ Doped with $\mathrm{Er}^{3+}$ and External Quantum Efficiency of Upconverter Solar Cell Devices under Broad-Band Excitation Considering Spectral Mismatch Corrections. Sol. Energy Mater. Sol. Cells 2014, 122, 197-207. 
(29) Turner, E.; Bakken, N.; Li, J. Cyclometalated Platinum Complexes with Luminescent Quantum Yields Approaching 100\%. Inorg. Chem. 2013, 52, 7344-7351.

(30) Gross, S.; Camozzo, D.; Di Noto, V.; Armelao, L.; Tondello, E. PMMA: A Key Macromolecular Component for Dielectric Low- $\kappa$ Hybrid Inorganic-Organic Polymer Films. Eur. Polym. J. 2007, 43, 673-696.

(31) Kuo, H.-H.; Zhu, Z.; Lee, C.-S.; Chen, Y.-K.; Liu, S.-H.; Chou, P.-T.; Jen, A.-K. Y.; Chi, Y. Bis-Tridentate Iridium(III) Phosphors with Very High Photostability and Fabrication of Blue-Emitting OLEDs. Adv. Sci. 2018, 5, 1-7.

(32) Crespo, M.; Martinez, M.; Sales, J.; Solans, X.; Font-Bardía, M. Syntheses and Mechanistic Studies in the Formation of Endo-and Exo-Cyclometalated Platinum Compounds of N-Benzylldenebenzylamines. Organometallics 1992, 11, 1288-1295.

(33) Clark, H. C.; Milne, C. R. Phosphorus-31 Nuclear Magnetic Resonance Spectra of Methylplatinum(II) and Methylpalladium(II) Cations Containing 4-Substituted Pyridine Ligands. Can. J. Chem. 1979, 57, 958-960.

(34) Rashidi, M.; Nabavizadeh, S. M.; Zare, A.; Jamali, S.; Puddephatt, R. J. Associative and Dissociative Mechanisms in the Formation of Phthalazine Bridged Organodiplatinum(II) Complexes. Inorg. Chem. 2010, 49, 8435-8443.

(35) Rendina, L. M.; Puddephatt, R. J. Oxidative Addition Reactions of Organoplatinum(II) Complexes with Nitrogen-Donor Ligands. Chem. Rev. 1997, 97, 1735-1754.

(36) Baar, C. R.; Carbray, L. P.; Jennings, M. C.; Puddephatt, R. J. Oxidative Addition to Diplatinum(II) Complexes: Stereoselectivity and Cooperative Effects. Organometallics 2000, 19, 2482-2497.

(37) Mastrocinque, F.; Anderson, C. M.; Elkafas, A. M.; Ballard, I. V.; Tanski, J. M. Synthesis, Characterization, and Photophysical Properties of Cyclometalated N-Heterocyclic Carbene Platinum(II) Complexes. J. Organomet. Chem. 2019, 880, 98-107.

(38) Anderson, C. M.; Mastrocinque, C.; Greenberg, M. W.; McClellan, I. C.; Duman, L.; Oh, N.; Mastrocinque, F.; Pizzuto, M.; Tran, K.; Tanski, J. M. Synthesis, Characterization, and Photophysical Properties of Bismetalated Platinum Complexes with Benzothiophene Ligands. J. Organomet. Chem. 2019, 882, 10-17.

(39) Kozhevnikov, V. N.; Durrant, M. C.; Williams, J. A. G. Highly Luminescent Mixed-Metal Pt(II)/Ir(III) Complexes: Bis-Cyclometalation of 4,6-Diphenylpyrimidine as a Versatile Route to Rigid Multimetallic Assemblies. Inorg. Chem. 2011, 50, 6304-6313.

(40) Hao, Z.; Meng, F.; Wang, P.; Wang, Y.; Tan, H.; Pei, Y.; Su, S.; Liu, Y. Dual Phosphorescence Emission of Dinuclear Platinum(II) Complex Incorporating Cyclometallating Pyrenyl-Dipyridine-Based Ligand and Its Application in near-Infrared Solution-Processed Polymer Light-Emitting Diodes. Dalton Trans. 2017, 46, 1625716268.

(41) Geist, F.; Jackel, A.; Winter, R. F. Dual Ligand-Based Fluorescence and Phosphorescence Emission at Room Temperature from Platinum Thioxanthonyl Complexes. Dalton Trans. 2015, 44, 3974-3987.

(42) Chi, C.; Im, C.; Wegner, G. Lifetime Determination of Fluorescence and Phosphorescence of a Series of Oligofluorenes. J. Chem. Phys. 2006, 124, No. 024907.

(43) Rajendra Kumar, G.; Thilagar, P. Tuning the Phosphorescence and Solid State Luminescence of Triarylborane-Functionalized Acetylacetonato Platinum Complexes. Inorg. Chem. 2016, 55, $12220-12229$.

(44) Alam, P.; Climent, C.; Alemany, P.; Laskar, I. R. "AggregationInduced Emission" of Transition Metal Compounds: Design, Mechanistic Insights, and Applications. J. Photochem. Photobiol., C 2019, 41, 100317.

(45) Chen, X.; Sun, Y.; Zhao, X.; Deng, X.; Yang, X.; Sun, Y.; Zhou, G.; Wu, Z. Mono-, Di- And Tri-Nuclear $\mathrm{Pt}^{\mathrm{II}}\left(\mathrm{C}^{\wedge} \mathrm{N}\right)(\mathrm{N}-$ Donor Ligand) $\mathrm{Cl}$ Complexes Showing Aggregation-Induced Phosphorescent Emission (AIPE) Behavior for Efficient Solution-Processed Organic Light-Emitting Devices. Mater. Chem. Front. 2021, 5, 4160-4173.
(46) Zhao, J.; Feng, Z.; Zhong, D.; Yang, X.; Wu, Y.; Zhou, G.; Wu, Z. Cyclometalated Platinum Complexes with Aggregation-Induced Phosphorescence Emission Behavior and Highly Efficient Electroluminescent Ability. Chem. Mater. 2018, 30, 929-946.

(47) Nakamaru, K. Synthesis, Luminescence Quantum Yields, and Lifetimes of Trischelated Ruthenium(II) Mixed-ligand Complexes Including 3,3'-Dimethyl-2,2'-bipyridyl. Bull. Chem. Soc. Jpn. 1982, 55, 2697-2705.

(48) Van Houten, J.; Watts, R. J. Temperature dependence of the photophysical and photochemical properties of the tris $(2,2$ 'bipyridyl)ruthenium(II) ion in aqueous solution. J. Am. Chem. Soc. 1976, 98, 4853-4858.

(49) Egami, T., Billinge, S. J. Underneath the Bragg Peaks: Structural Analysis of Complex Materials, 2nd Ed.; Elsevier: Amsterdam, 2012; DOI: 10.1016/B978-0-08-097133-9.00003-4.

(50) Prill, D.; Juhás, P.; Schmidt, M. U.; Billinge, S. J. L. Modelling Pair Distribution Functions (PDFs) of Organic Compounds: Describing Both Intra- and Intermolecular Correlation Functions in Calculated PDFs. J. Appl. Crystallogr. 2015, 48, 171-178.

(51) Belviso, B. D.; Marin, F.; Fuertes, S.; Sicilia, V.; Rizzi, R.; Ciriaco, F.; Cappuccino, C.; Dooryhee, E.; Falcicchio, A.; Maini, L.; et al. Structural Insights into the Vapochromic Behavior of Pt- And Pd-Based Compounds. Inorg. Chem. 2021, 60, 6349-6366.

(52) Rademacher, N.; Daemen, L. L.; Chronister, E. L.; Proffen, T. Pair Distribution Function Analysis of Molecular Compounds: Significance and Modeling Approach Discussed Using the Example of $p$-Terphenyl. J. Appl. Crystallogr. 2012, 45, 482-488.

(53) Juhás, P.; Cherba, D. M.; Duxbury, P. M.; Punch, W. F.; Billinge, S. J. L. Ab Initio Determination of Solid-State Nanostructure. Nature 2006, 440, 655-658.

(54) Alam, P.; Climent, C.; Kaur, G.; Casanova, D.; Roy Choudhury, A.; Gupta, A.; Alemany, P.; Laskar, I. R. Exploring the Origin of Aggregation Induced Emission Activity and Crystallization Induced Emission in Organometallic Iridium(III) Cationic Complexes: Influence of Counterions. Cryst. Growth Des. 2016, 16, 5738-5752.

(55) Shan, G.-G.; Li, H.-B.; Qin, J.-S.; Zhu, D.-X.; Liao, Y.; Su, Z.-M. Piezochromic Luminescent (PCL) Behavior and Aggregation-Induced Emission (AIE) Property of a New Cationic Iridium(III) Complex. Dalton Trans. 2012, 41, 9590-9593.

(56) Chen, Z.; Zhang, J.; Song, M.; Yin, J.; Yu, G.-A.; Liu, S. H. A Novel Fluorene-Based Aggregation-Induced Emission (AIE)-Active Gold(I) Complex with Crystallization-Induced Emission Enhancement (CIEE) and Reversible Mechanochromism Characteristics. Chem. Commun. 2015, 51, 326-329.

(57) Pasha, S. S.; Alam, P.; Sarmah, A.; Roy, R. K.; Laskar, I. R. Encapsulation of Multi-Stimuli AIE Active Platinum(II) Complex: A Facile and Dry Approach for Luminescent Mesoporous Silica. RSC Adv. 2016, 6, 87791-87795.

(58) Bochevarov, A. D.; Harder, E.; Hughes, T. F.; Greenwood, J. R.; Braden, D. A.; Philipp, D. M.; Rinaldo, D.; Halls, M. D.; Zhang, J.; Friesner, R. A. Jaguar: A High-Performance Quantum Chemistry Software Program with Strengths in Life and Materials Sciences. Int. J. Quantum Chem. 2013, 113, 2110-2142.

(59) Hanwell, M. D.; Curtis, D. E.; Lonie, D. C.; Vandermeersch, T.; Zurek, E.; Hutchison, G. R. Avogadro: An Advanced Semantic Chemical Editor, Visualization, and Analysis Platform. Aust. J. Chem. 2012, 4, 1-17.

(60) Lakowicz, J. R. Principles of Fluorescence Spectroscopy; 3rd Ed.; Springer US: 2006.

(61) Sheldrick, G. M. SHELXT - Integrated Space-Group and Crystal-Structure Determination. Acta Crystallogr., Sect. A: Found. Adv. 2015, 71, 3-8.

(62) Sheldrick, G. M. Crystal Structure Refinement with SHELXL. Acta Crystallogr., Sect. C: Struct. Chem. 2015, 71, 3-8.

(63) Chupas, P. J.; Qiu, X.; Hanson, J. C.; Lee, P. L.; Grey, C. P.; Billinge, S. J. L. Rapid-Acquisition Pair Distribution Function (RAPDF) Analysis. J. Appl. Crystallogr. 2003, 36, 1342-1347. 
(64) Ashiotis, G.; Deschildre, A.; Nawaz, Z.; Wright, J. P.; Karkoulis, D.; Picca, F. E.; Kieffer, J. The Fast Azimuthal Integration Python Library: PyFAI. J. Appl. Crystallogr. 2015, 48, 510-519.

(65) Juhás, P.; Davis, T.; Farrow, C. L.; Billinge, S. J. L. PDFgetX3: A Rapid and Highly Automatable Program for Processing Powder Diffraction Data into Total Scattering Pair Distribution Functions. J. Appl. Crystallogr. 2013, 46, 560-566.

(66) Yang, X.; Juhas, P.; Farrow, C. L.; Billinge, S. J. L. XPDFsuite: An End-to-End Software Solution for High Throughput Pair Distribution Function Transformation. Visualization Anal. 2014, 1-4.

(67) Juhás, P.; Farrow, C. L.; Yang, X.; Knox, K. R.; Billinge, S. J. L. Complex Modeling: A Strategy and Software Program for Combining Multiple Information Sources to Solve Ill Posed Structure and Nanostructure Inverse Problems. Acta Crystallogr., Sect. A 2015, 71, 562-568.

(68) Price, J. H.; Williamson, A. N.; Schramm, R. F.; Wayland, B. B. Palladium(II) and Platinum(II) Alkyl Sulfoxide Complexes. Examples of Sulfur-Bonded, Mixed Sulfur- and Oxygen-Bonded, and Totally Oxygen-Bonded Complexes. Inorg. Chem. 1972, 11, 1280-1284.

(69) Mastrocinque, C. P. Synthesis, Characterization, and Photophysical Properties of Cyclometalated Platinum(II) Complexes; Bard College, 2019.

(70) Crespo, M.; Martín, R.; Calvet, T.; Font-Bardía, M.; Solans, X. Novel Platinum(II) Compounds with N-Benzylidenebenzylamines: Synthesis, Crystal Structures and the Effect of Cis or Trans Geometry on Cycloplatination. Polyhedron 2008, 27, 2603-2611. 